\title{
BMJ Open Predictors of controlled prescription drug non-medical and lifetime use among patients accessing public mental health services in Uganda: a cross- sectional study
}

Pakoyo Fadhiru Kamba (D) , John Mulangwa, ${ }^{1}$ Peter Kageni, ${ }^{1}$ Sulah Balikuna, ${ }^{1}$ Allan Kengo, ${ }^{2}$ Brian Byamah Mutamba, ${ }^{3}$ Nelson Sewankambo, ${ }^{4}$ Richard Odoi Adome, ${ }^{1}$ Pauline Byakika-Kibwika ${ }^{4}$

To cite: Kamba PF, Mulangwa J, Kageni $\mathrm{P}$, et al. Predictors of controlled prescription drug nonmedical and lifetime use among patients accessing public mental health services in Uganda: a cross-sectional study. BMJ Open 2021;11:e037602. doi:10.1136/ bmjopen-2020-037602

- Prepublication history and additional supplemental material for this paper is available online. To view these files, please visit the journal online (http://dx.doi. org/10.1136/bmjopen-2020037602).

Received 10 February 2020 Revised 02 February 2021 Accepted 12 February 2021

Check for updates

(c) Author(s) (or their employer(s)) 2021. Re-use permitted under CC BY-NC. No commercial re-use. See rights and permissions. Published by BMJ.

For numbered affiliations see end of article.

Correspondence to Dr Pakoyo Fadhiru Kamba kambaf2000@yahoo.com

\section{ABSTRACT}

Objectives We determined the prevalence of controlled prescription drug (CPD) non-medical and lifetime use and their predictors among patients at three public psychiatric clinics in Uganda to identify missed care opportunities, enhanced screening priorities, and drug control needs.

Methods A cross-sectional survey of 1275 patients was performed from November to December 2018. Interviewer-administered semi-structured questionnaires, desk review guide and urine drug assays were employed. Questionnaire recorded CPD non-medical and illicit drug use history from patients' files, CPD lifetime use and risk factors. Desk review guide recorded recently prescribed drugs in patients' files to corroborate with urine assays. Predictors were analysed by multivariate logistic regression.

Results From desk review, 145 (11.4\%) patients had history of CPD non-medical use and $36(2.8 \%)$ had used illicit drugs. Of 988 patients who provided urine, 166 (16.8\%) self-medicated CPDs, particularly benzodiazepines while $12(1.2 \%)$ used illicit drugs. Of those with drugpositive urine, $123(69.1 \%)$ had no documented history of CPD non-medical and illicit drug use. Being an inpatient $(\mathrm{OR}=10.90, \mathrm{p}<0.001)$ was independently associated with CPD non-medical use. Additionally, being an inpatient $(0 R=8.29, p<0.001)$ and tobacco consumption $(0 R=1.85$, $p=0.041)$ were associated with CPD non-medical and illicit drug use combined. Among participants, 119 (9.3\%) reported CPD lifetime use, and this was independently associated with education level $(0 R=2.71, p<0.001)$ and history of treatment for substance abuse $(\mathrm{OR}=2.08$, $p=0.018)$.

Conclusions CPD non-medical use is common among Uganda's psychiatric patients, and more prevalent than illicit drug use. Rapid diagnostic assays may be needed in psychiatric care in resource limited settings. It is necessary to assess how CPD non-medical use impacts mental care outcomes and patient safety. High risk groups like inpatients and tobacco consumers should be prioritised in psychiatric screening.
Strengths and limitations of this study

- A major strength of this study is the large sample size (high power), fair representation of different psychiatric disorders and patient categories (inpatients vs outpatients) in the sample and wide geographical coverage of Uganda.

- It also derives strength from the combined use of patient records and urine drug assays to detect nonmedical use.

- It is the first study of controlled prescription drug non-medical use and its predictors in any population group in Uganda and most of sub-Saharan Africa.

- One limitation is that we used a convenience sample of only psychiatric patients attending public clinics which excluded those who are not in care and those who attend private clinics.

- We did not investigate if the controlled prescription drug non-medical use was a drug use disorder or not, which limits our insights on the impact of the observed behaviour on mental health outcomes.

\section{BACKGROUND}

Drugs that moderate the function of the central nervous system such as opioids, stimulants, sedatives, hypnotics and anaesthetics are the backbone of modern operative surgery, mental health and neurology. However, these drugs induce such strong reward feelings that they are prone to nonmedical use in which they are consumed without prescriber authorisation, in unapproved doses and routes of administration and for non-therapeutic causes. ${ }^{1-3}$ Consequently, these drugs are judiciously controlled to prevent non-medical use, hence the synonym controlled prescription drugs (CPDs). ${ }^{4-6}$ As seen in the prescription opioid and amphetamine-group (amphetamine and 
methamphetamine) drugs non-medical use escalations in high-income countries, ${ }^{7-12}$ deterrence of CPD nonmedical use can be difficult. Less economically endowed countries have not been spared too. Among Nigeria's 98 million of 15-64year olds, a recent household survey found that $4.7 \%$ had engaged in prescription opioid nonmedical use in the past year, accounting for $32 \%$ of all non-medical drug use in the country. ${ }^{13}$ There are also escalations in non-medical use of methamphetamine in South Africa ${ }^{12} 14$ and tramadol in West and North Africa. ${ }^{15}$ Globally, at least 60 countries have a high burden of benzodiazepine non-medical use. ${ }^{11}$

Non-medical CPD use produces devastating health outcomes like neurological impairment and severe mental disorders. ${ }^{816}$ Opioid non-medical use exacerbates the prevalence of suicides and common mental disorders while amphetamines cause drug-induced psychosis, anxiety and depression. ${ }^{8}{ }^{16}$ Independent association has been reported between drug dependence and psychiatric disorders in patients with HIV. ${ }^{17} \mathrm{~A}$ higher risk of incident psychosis has also been reported among patients with attention deficit-hyperactivity disorder on medically prescribed amphetamine treatment compared with methylphenidate. ${ }^{18}$ Meanwhile, benzodiazepines fatally interact with other central nervous system (CNS) suppressants and are involved in 30\% of prescription drug-related deaths, trailing only opioids at $75 \% .{ }^{19}$ In some settings, benzodiazepines play a part in $80 \%$ of accidental opioidrelated overdose deaths. ${ }^{19}$

Intriguingly, mental disorders exacerbate the propensity for CPD non-medical and illicit drug use. ${ }^{20-22}$ A strong association between severe mental distress and benzodiazepine use disorders has been reported among club dwellers in Florida, USA. ${ }^{23}$ Problem drug use, depressive and other psychiatric disorders, and post-traumatic stress disorder increase likelihood of opioid non-medical use. ${ }^{20-22 ~} 24$ There is also association between mental disorders and lifetime prescription opioid use. A longitudinal US study found association between common mental disorders and prescription opioid use, and between problem drug use and prescription opioid use..$^{25}$ In patients with HIV, independent associations between psychiatric disorders and drug dependence ${ }^{17}$ and between depression and repeat opioid prescriptions ${ }^{24}$ have been recorded. Association of depression, anxiety disorders, panic attacks and post-traumatic stress disorder with prescription opioid non-medical use has also been reported among patients on chronic opioid therapy and injection drug users. ${ }^{26-29}$ Elsewhere, a study of 194 outpatients with schizophrenia in Australia found high levels of substance and drug nonmedical use with prevalence of $26.8 \%$ and $59.8 \%$ in the last 6 months and lifetime, respectively. ${ }^{30}$

Thus, mental disorders and CPD non-medical use feed on each other. If not mitigated, CPD non-medical use among psychiatric patients may compromise treatment outcomes, medication adherence and quality of life. Critically, non-medical use of one drug typically increases likelihood of other drug use disorders. ${ }^{16} 3132$ Thus, the burden and predictors of CPD non-medical use in highrisk populations ought to be understood. Unfortunately, data on CPD non-medical use in low-income countries are limited, ${ }^{16}$ particularly in sub-Saharan Africa. ${ }^{33}$ Therefore, we determined the prevalence of CPD non-medical and lifetime use among Uganda's mental health patients and associated factors. Factors known to favour CPD nonmedical and illicit drug use in literature informed our conceptual design. These include socio-demographics like age, sex, marital status, religion, employment status, years of schooling; tobacco consumption; alcohol consumption; chronic pain; illicit drug use history; and occupation. $716172122303234-38$

\section{METHODS \\ Study design}

A cross-sectional survey of CPD non-medical and lifetime use and associated factors was conducted in a convenience sample of 1275 psychiatric patients at the mental health clinics of three referral hospitals in Uganda in November and December 2018.

\section{Study setting}

Study was conducted at Mulago Hospital, Butabika Hospital and Mbale Hospital. Located in Uganda's capital Kampala in Central Uganda, Mulago and Butabika hospitals are the country's two national referral hospitals where the highest level of specialist care is provided. Mbale Hospital is located in the Eastern regional business district of Mbale. All three hospitals provide psychiatric care, though Butabika is the major provider and the national referral psychiatric hospital. Reported annual psychiatric patient attendances are Butabika (6200 inpatients, 56000 outpatients); Mulago (400 inpatients, 800 outpatients); and Mbale (400 inpatients, 2500 outpatients). ${ }^{39} 40$

\section{Participants}

Sample size was computed from a reported study population of patients that attend mental health services of the three hospitals weekly, namely 135 inpatient admissions and 1140 outpatients ${ }^{39}{ }^{40}$ in two steps. First, the sample size for a homogeneous population was computed using the Cochran formula for categorical data ${ }^{41}$ at $5 \%$ margin of error, $95 \%$ confidence level and effect prevalence of $40 \%,{ }^{21}$ followed by a Cochran correction. ${ }^{41}$ This yielded a sample size of 285 which was finally adjusted to 1277 with a design effect of 4.48 to cater for variation in living environment and severity of mental illness between inpatients and outpatients. Multistage, proportionate stratified sampling was used to distribute the 1277 samples into inpatients and outpatients, and into the three hospitals. The sample was first distributed into 135 inpatients and 1142 outpatients based on literature, ${ }^{39} 40$ after which it was adjusted to 257 inpatients and 1020 outpatients to match the prevailing weekly load of each type of patient in the hospitals based on guidance obtained during predata collection site visits. Overall, 1275 participants (1196 
Butabika, 56 Mbale and 23 Mulago) were enrolled into the study by convenience consecutive sampling based on availability and willingness to participate in the study. All clinician (psychiatrist or psychiatric clinical officer) diagnosed patients attending the mental health clinics during data collection were sampled. Paediatric patients below adolescence (less than 10 years of age), severely ill and non-speakers of the two widely spoken Ugandan languages in which the questionnaire was written (English and Luganda) were excluded.

\section{Data collection}

Data on both CPD non-medical use and illicit drug use were collected. Illicit drugs are those narcotic and psychotropic drugs that are prohibited from medical use by international law due to higher risk of dependence than benefits. ${ }^{16}$

A combination of interviewer-administered semistructured questionnaire, urine drug immunoassays and desk review guide for drugs prescribed for patients in their hospital files was used. The questionnaire inquired into the presence of documented clinician's diagnosis of CPD non-medical and illicit drug use in a patient's lifetime in their hospital files, as well as whether a urine sample was provided by the patient for drug analysis. The questionnaire also recorded self-reported history of lifetime use of individual CPDs and how these drugs were introduced to the participants the first time they used them. Drug immunoassays assessed for presence of both CPDs and illicit drugs in a participant's urine. These assays employed the 10-drug vaxpert rapid test cups (Vaxpert Inc, Miami, Florida, USA) that detect barbiturates, benzodiazepines, morphine, methadone, amphetamine, methamphetamine, tricyclic antidepressants, methylenedioxymethamphetamine, cocaine and marijuana. The assay uses monoclonal antibodies to detect elevated levels of these drugs and their metabolites. Urine specimen were collected in labelled $120 \mathrm{~mL}$ plastic urine bottles, stored in cool boxes and analysed at the Department of Pharmacy, Makerere University. Test results were read within 5 min of adding urine to the vaxpert cup. The desk review guide assessed only recent CPD use by recording all medications in the patient's last prescription (from hospital patients' files) and date of last dose. Data from this guide were used to determine if a positive CPD urine assay was due to recent medical use or not. A positive CPD urine result was deemed non-medical use if desk review guide data had no CPD among drugs in a participant's recent prescription. The questionnaire and review guide were designed by the study team.

The questionnaire also inquired into sociodemographic and other participant attributes that have been associated with controlled drug non-medical use in previous studies. These include age, sex, marital status, religion, employment status, years of schooling, tobacco consumption, alcohol consumption, chronic pain, illicit drug use history and occupation. Numerical variables such as age were collected as individual values after which binary categories for bivariate and multivariate logistic regression were created using the median as cut-off.

\section{Study outcomes}

There were three study outcomes: (1) Prevalence of CPD non-medical use. (2) Prevalence of CPD non-medical and illicit drug use combined. (3) Prevalence of self-reported CPD lifetime use. We defined CPD non-medical use in two ways; (a) if patient posted a positive urine assay for given CPDs but desk review guide found no medical use of such CPDs in their last prescription; (b) if questionnaire found a documented clinician's diagnosis of CPD drug use disorder in a patient's lifetime in their hospital files. Illicit drug use was also defined in two ways; (a) all patients with positive urine assays for any illicit drug; (b) if questionnaire found a documented clinician's diagnosis of illicit drug use disorder in a patient's lifetime in their hospital files.

Self-reported lifetime use was measured using a checklist of 22 commonly prescribed CPD products, comprising 12 opioids, 2 amphetamine-group products, 2 intravenous anaesthetics, 3 barbiturates and 3 benzodiazepines. A patient had self-reported CPD lifetime use if they responded affirmatively as having ever used at least 1 of the 22 CPD products.

\section{Data analyses}

A single data entry template merging the questionnaire and desk review guide was created in EpiData V.3.1, followed by data entry. Before entry, desk review guide data on drugs recently prescribed in the patients' files was examined by the first author and the drugs documented therein were categorised as CPD or not, along with the class of the CPD (opioids, benzodiazepines, barbiturates, amphetamines, anaesthetics). After data entry, the data set was cleaned and transcribed into SPSS V.13. Final data cleaning, descriptive analysis and bivariate analysis of predictors of CPD nonmedical use and lifetime use were done in SPSS. We then transcribed SPSS data into Stata V.12 after which multivariate logistic regression was done. Regression analysis was guided by a conceptual framework informed by literature. Multivariate regression employed backward elimination in which factors with statistically significant associations from bivariate analysis were fixed while sequentially removing those with weak associations from the multivariate model until only those with $\mathrm{p}$ values less than 0.5 remained. All cases with missing data on a given variable were excluded from analyses involving that variable.

\section{Patient and public involvement}

The public was involved in the design of study as the institutional review board and Uganda National Council of Science and Technology guided improvements in the protocol before approval. Authorities from the study sites also recommended further refinements in the study protocol before issuing administrative clearance. Patients were involved in assessing the risks of the study during consenting. 


\begin{tabular}{|c|c|c|c|}
\hline Characteristic & Category & $\begin{array}{l}\text { Sample } \\
\text { size, N }\end{array}$ & $\begin{array}{l}\text { Frequency } \\
\text { n (\%) }\end{array}$ \\
\hline \multirow[t]{2}{*}{ Sex of patient } & Male & 1275 & $681(53.4)$ \\
\hline & Female & 1275 & $594(46.6)$ \\
\hline \multirow{2}{*}{$\begin{array}{l}\text { Age of patient } \\
\text { (years) }\end{array}$} & $\leq 25$ & 1275 & $290(22.7)$ \\
\hline & $>25$ & 1275 & 985 (77.3) \\
\hline \multirow[t]{2}{*}{ Type of patient } & Inpatient & 1275 & $257(20.2)$ \\
\hline & Outpatient & 1275 & $1018(79.8)$ \\
\hline \multirow{3}{*}{$\begin{array}{l}\text { Religious } \\
\text { background of } \\
\text { patient }\end{array}$} & Christian & 1275 & $1071(84.0)$ \\
\hline & Muslim & 1275 & $198(15.5)$ \\
\hline & Other & 1275 & $6(0.5)$ \\
\hline \multirow{2}{*}{$\begin{array}{l}\text { Marital status of } \\
\text { patient }\end{array}$} & Single & 1275 & $916(71.8)$ \\
\hline & Married & 1275 & $359(28.2)$ \\
\hline \multirow[t]{2}{*}{$\begin{array}{l}\text { Highest education } \\
\text { level }\end{array}$} & $\begin{array}{l}\text { Secondary school } \\
\text { and below }\end{array}$ & 1275 & $979(76.8)$ \\
\hline & $\begin{array}{l}\text { Beyond secondary } \\
\text { school }\end{array}$ & 1275 & $296(23.2)$ \\
\hline \multirow[t]{2}{*}{ Employment status } & Employed & 1272 & $554(43.6)$ \\
\hline & Unemployed & 1272 & $718(56.4)$ \\
\hline \multirow[t]{7}{*}{$\begin{array}{l}\text { Most represented } \\
\text { occupations }\end{array}$} & $\begin{array}{l}\text { Peasant, informal } \\
\text { sector }\end{array}$ & 1275 & $654(51.3)$ \\
\hline & Student & 1275 & $80(6.3)$ \\
\hline & Teacher & 1275 & $57(4.5)$ \\
\hline & Driver & 1275 & $23(1.8)$ \\
\hline & $\begin{array}{l}\text { Security/armed } \\
\text { forces }\end{array}$ & 1275 & $21(1.6)$ \\
\hline & Administrator & 1275 & $20(1.6)$ \\
\hline & Medical worker & 1275 & $20(1.6)$ \\
\hline \multirow{2}{*}{$\begin{array}{l}\text { Urine specimen } \\
\text { provided }\end{array}$} & Yes & 1275 & $988(77.5)$ \\
\hline & No & 1275 & $287(22.5)$ \\
\hline
\end{tabular}

\section{RESULTS}

Responses were received from 1275 participants of which $988(77.5 \%)$ volunteered urine samples for CPD screening. Among these, 1196 were from Butabika, 23 were from Mulago and 56 were from Mbale hospitals.

\section{Characteristics of participants}

As shown in table 1, most participants were outpatients of Christian faith, single marital status, peasants, informal sector workers and greater than 25 years of age. There was fair distribution of participants by sex and employment status.

\section{Prevalence of CPD non-medical use among patients accessing mental health services}

Hospital files for 1267 of the 1275 participants enrolled into the study were examined for history of clinician's diagnosis of CPD non-medical and/or illicit drug use in patient's lifetime. Files for eight participants were not accessible. We found that $181(14.3 \%)$ of the participants had history of
Table 2 Prevalence of documented controlled prescription drug non-medical and illicit drug use by drug class

\begin{tabular}{lll}
\hline Drug class & $\begin{array}{l}\text { Sample } \\
\text { size, N }\end{array}$ & $\begin{array}{l}\text { Frequency } \\
\mathbf{n}(\%)\end{array}$ \\
\hline Opioids* & 1267 & $1(0.1)$ \\
\hline Benzodiazepines $\dagger$ & 1267 & $142(11.2)$ \\
Opioids plus benzodiazepines $\ddagger$ & 1267 & $1(0.1)$ \\
Benzodiazepines plus illicit drugs§ & 1267 & $1(0.1)$ \\
\hline Illicit drugs $\mid$ & 1267 & $36(2.8)$ \\
\hline
\end{tabular}

*Three were documented for same patient, namely, pethidine, morphine and tramadol.

†Only diazepam was documented.

†This was a case of dual use of diazepam and codeine.

$\S$ This was a case of dual use of diazepam and khat.

IOf the 36 cases, $24(66.7 \%)$ are cannabis, $7(19.4 \%)$ are cannabis

and khat, $3(8.3 \%)$ are khat, $1(2.8 \%)$ is heroin and $1(2.8 \%)$ is unspecified illicit substance.

clinician's diagnosed CPD non-medical and illicit drug use disorders of which 144 (11.4\%) had CPD non-medical use only, $1(0.08 \%)$ had both CPD non-medical and illicit drug use and $36(2.8 \%)$ had illicit drug use only, particularly cannabis. Among the CPDs, highest non-medical consumption was with benzodiazepines, alone or in combination with opioids and illicit drugs (table 2).

Among the 988 participants who provided urine, 166 (16.8\%) who had not been recently prescribed any CPDs in their hospital records tested positive for these drugs. Another $12(1.2 \%)$ participants tested positive for illicit drugs, mainly $\Delta 9$-tetrahydrocannabinol, a constituent of illicit cannabis. The overall burden of CPD non-medical and illicit drug use combined was $178(18.0 \%)$ of the 988 participants. When categorised by mental disorder diagnosis documented in patients' files, the prevalence of CPD non-medical and illicit drug use combined was similar but slightly higher among patients with psychotic disorders than those with mood and other non-drug induced disorders (online supplemental table 1).

Among the CPDs, the highest non-medical consumption detected in urine was for benzodiazepines, alone and occasionally in combination with barbiturates and illicit drugs (table 3). Out of the 178 patients with CPD nonmedical and illicit drug use by urine assay, 22 (12.4\%) had multiple controlled drugs, particularly benzodiazepines and cannabis. On further analysis, 123 (69.1\%) of the drug positive urine was from patients with no documented history of clinician's diagnosed CPD non-medical and illicit drug use in their lifetime (online supplemental table 2).

\section{Predictors of urine-positive CPD non-medical use among} patients accessing mental health services

After controlling for sex and current alcohol consumption, the type of patient was independently associated with urine-positive CPD non-medical use (table 4). The odds of urine-positive CPD non-medical use were significantly higher among inpatients than outpatients. 
Table 3 Prevalence of urine detected controlled prescription drug non-medical and illicit drug use by drug class

\begin{tabular}{|c|c|c|}
\hline Drug class & $\begin{array}{l}\text { Sample } \\
\text { size, } N\end{array}$ & $\begin{array}{l}\text { Frequency } \\
\text { n (\%) }\end{array}$ \\
\hline Opioids & 988 & $1(0.1)$ \\
\hline Amphetamines & 988 & $3(0.3)$ \\
\hline Amphetamines plus illicit drugs ${ }^{*} \dagger$ & 988 & $1(0.1)$ \\
\hline Benzodiazepines & 988 & $138(14.0)$ \\
\hline Barbiturates & 988 & $2(0.2)$ \\
\hline Benzodiazepines plus barbituratesł & 988 & $1(0.1)$ \\
\hline Benzodiazepines plus illicit drugs* & 988 & $20(2.0)$ \\
\hline Illicit drugs*§ & 988 & $12(1.2)$ \\
\hline
\end{tabular}

${ }^{*}$ Assay tested for $\Delta 9$-tetrahydrocannabinol (THC), cocaine and methylenedioxymethamphetamine (MDMA).

†THC was the illicit drug in both. Among the 166 participants who tested positive for controlled prescription drug non-medical use, the prevalence is 159 (95.8\%) benzodiazepines, 4 (2.4\%) amphetamines, $3(1.8 \%)$ barbiturates and $1(0.6 \%)$ opioids. $\ddagger$ A total of $21(13.2 \%)$ of the 159 participants with benzodiazepines tested positive for other controlled drugs. $\S$ Of these, 10 and 2 participants tested positive for THC and MDMA, respectively.

\section{Predictors of urine-positive CPD non-medical and illicit drug use combined among patients accessing mental health services}

After controlling for sex and current alcohol consumption, the type of patient and current tobacco consumption were independently associated with urine-positive CPD non-medical and illicit drug use combined (table 5). The odds of urine-positive CPD non-medical and illicit drug use combined were significantly higher among inpatients and those with current tobacco consumption than their corresponding counterparts.

\section{Prevalence of self-reported CPD lifetime use among patients accessing mental health services}

Of the 1275 participants, 119 (9.3\%) reported having ever used CPDs in their lifetime. Most exposure was to diazepam, tramadol capsules, codeine, oral morphine, tramadol injection and amphetamine in descending order (online supplemental table 3). Among those who reported CPD lifetime use, about 25\% first used the drug without medical authorisation either through selfprescription or friends' influence (online supplemental table 4). Lastly, we found that first time CPD use was occasioned by treatment for mental illness and restlessness, operative pain and lack of sleep and pressure from friends (online supplemental table 5).

\section{Predictors of self-reported CPD lifetime use among patients accessing mental health services}

After controlling for age, sex, employment status, history of traumatic injury and current tobacco consumption, education level and history of treatment at a substance abuse facility were associated with self-reported CPD lifetime use (table 6). The odds of CPD lifetime use were significantly higher among patients educated beyond secondary school and those with history of treatment at a substance abuse facility.

\section{DISCUSSION}

Understanding the interplay between mental disorders and CPD non-medical use can enable improvements in mental health treatment outcomes. We found a high prevalence of CPD non-medical use among patients with mental disorders using both document review (11.4\%) and urine assays (17\%). This prevalence is two-to-three fold the $5.5 \%$ global prevalence of controlled drug nonmedical use in the general population. ${ }^{42}$ Similar findings have been reported elsewhere. In Australia, 11.3\% of schizophrenia outpatients had lifetime history of prescription drug use disorder and $27.8 \%$ tested positive to recent controlled drug use. ${ }^{30} \mathrm{~A}$ recent meta-analysis of stimulant use disorders in hospital patients with psychosis generated a pooled prevalence of $13.9 \%{ }^{43}$ These and our data suggest that having a mental illness provides similar risk for controlled drug abuse in different socio-economic and geographical settings.

Controlled drug non-medical use exacerbates HIV transmission and mental disorders. ${ }^{12} 16$ Thus, controlled drug non-medical use among Uganda's mental health patients needs mitigation. Multipronged strategies could achieve this, including deployment of rapid drug assays for enhanced detection of controlled drug nonmedical use and strengthening CPD regulation. Uganda's specialist mental health clinics lack assay kits for controlled drugs and rely on clinical screening/assessment to identify controlled drug non-medical use ${ }^{44}$ yet assays are important because patients commonly conceal drug use in fear of legal, social and cultural repercussions. ${ }^{131619}$ We found that clinical screening had missed about $70 \%$ of patients taking CPDs and illicit drugs. In Australia, urine assay detected drugs in one-third of patients who had reported zero recent drug use. ${ }^{30}$ Therefore, clinical screening alone precludes many patients with drug use disorders from receiving care. Besides, there is need to understand how mental patients obtain CPDs for non-medical use considering that Uganda's laws restrict supply to doctor authorised prescriptions. ${ }^{456}$

Non-medical use of controlled drugs among patients accessing mental health services in Uganda involved mostly benzodiazepines and illicit cannabis. Benzodiazepines were particularly popular, with a total prevalence of $16.1 \%$, five times that of cannabis at $3.3 \%$. Our cannabis use findings are lower than the $17 \%$ reported previously among mental health patients by Awuzu and coworkers. ${ }^{44}$ Comparison of our prevalence for recent and historical controlled drug use showed a similar pattern. Benzodiazepines still dominated the historical prevalence at $11.4 \%$ followed by cannabis at a distant $2.9 \%$. For both current and historical non-medical use, opioids were far less involved than in high-income settings. ${ }^{30}$ 


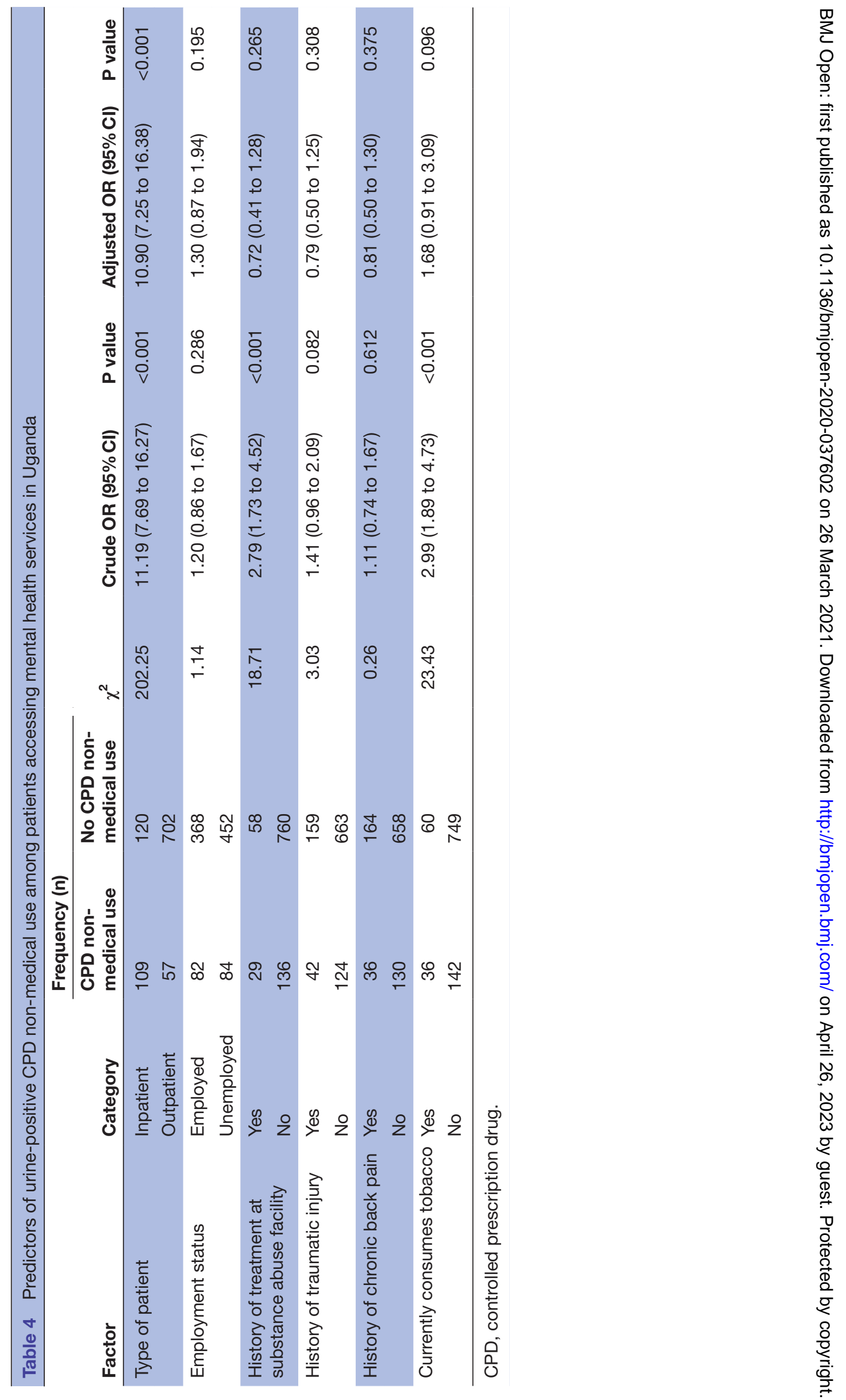




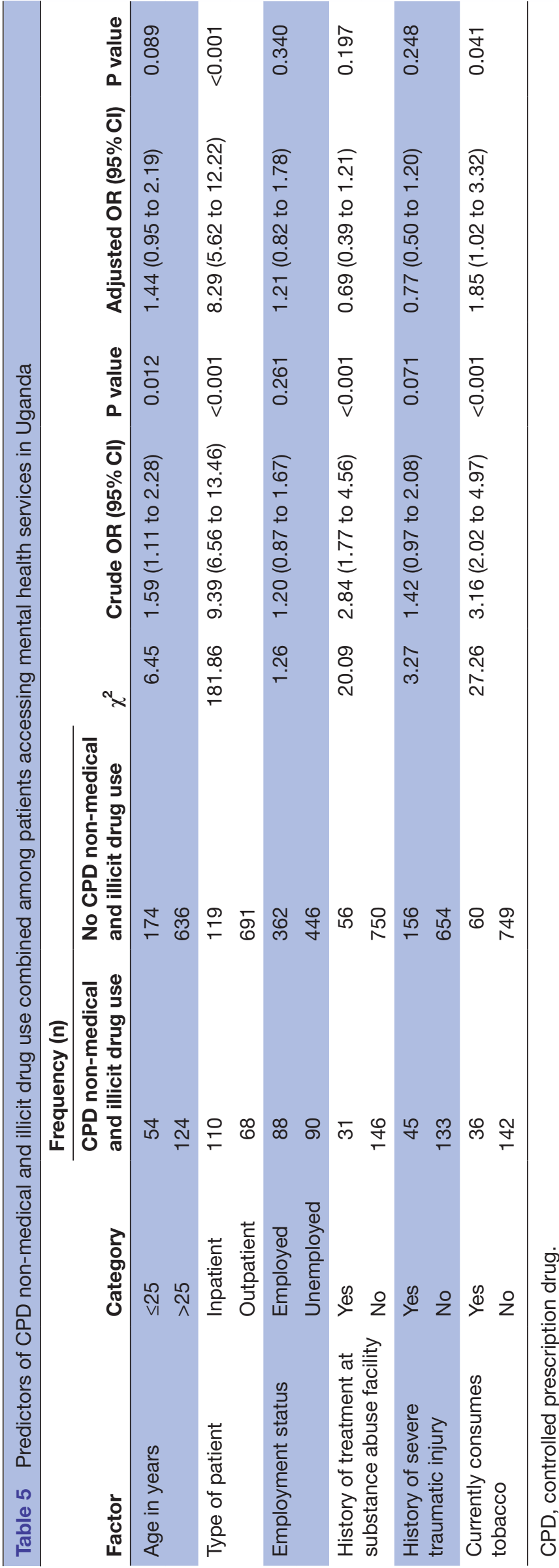

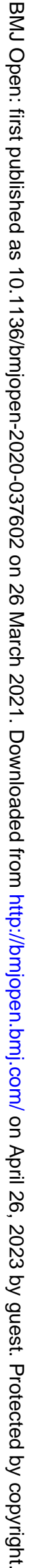




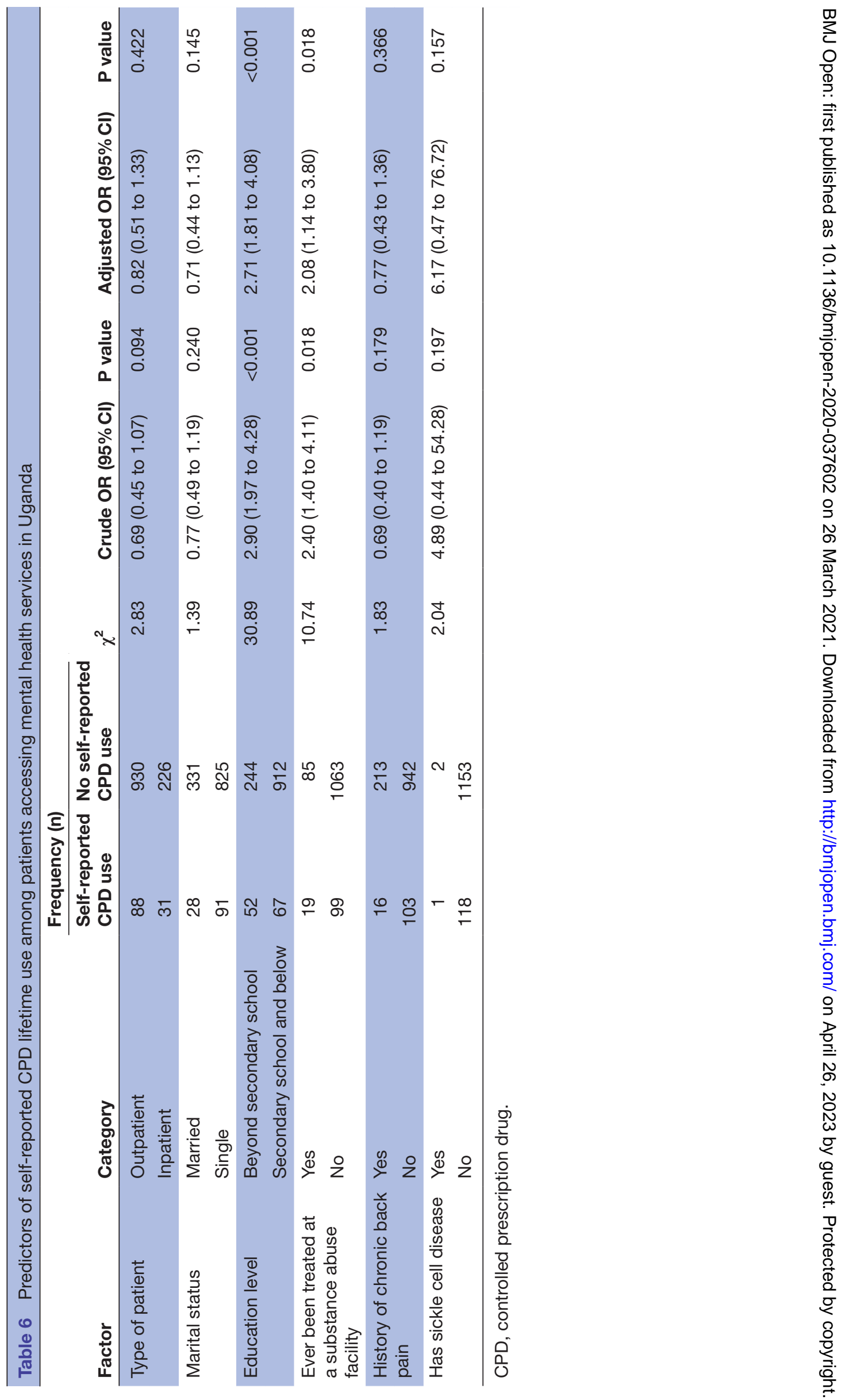


Although benzodiazepines non-medical use is elevated in psychiatric patients globally, ${ }^{48}$ there is high variation in dominant drug classes by country. Among inpatient psychiatric patients in Germany, benzodiazepines had the highest prevalence among those with drug use disorders followed by barbiturates, psychostimulants and opioids. ${ }^{47}$ In contrast, an Australian study of psychosis outpatients had cannabis leading lifetime non-medical use ahead of amphetamines, benzodiazepines and opioids ${ }^{30}$ Cannabis still led in recent use prevalence in that study followed by benzodiazepines, opioids and amphetamines. ${ }^{30}$ The prevalence of amphetamine non-medical use in Uganda's psychiatric patients falls short of the global prevalence of stimulant use disorders in this population which is $8.9 \%$ with highs of $30 \% .{ }^{43}$ Similarly, the $0.1 \%$ prevalence of prescription opioid non-medical use among Uganda's mental patients contrasts with the prevalence of chronic opioid use of $8.6 \%$ to $11 \%$ in the USA. ${ }^{21}$ Lastly, the drug class use pattern among Uganda's mental patients differs from global profiles for the general population. Globally, cannabis leads in controlled drug non-medical use followed by amphetamines. ${ }^{36}$ In the USA, opioids top tranquillisers and stimulants. ${ }^{7}{ }^{49}$ In Europe, sedatives edge opioids and stimulants. ${ }^{3}$ In Nigeria, cannabis leads followed by prescription opioids; sedatives and amphetamines score low. ${ }^{13}$

The high burden of benzodiazepine non-medical use transcends 60 countries. ${ }^{11}$ As CNS depressants, benzodiazepines cause fatal interactions with other CNS suppressants like opioids, other sedatives, hypnotics, neuroleptics and alcohol. They are involved in 30\% of prescription drug-related deaths, trailing only opioids at $75 \% .{ }^{19}$ Benzodiazepines have also been implicated in $80 \%$ of accidental opioid-related overdose deaths in some settings. ${ }^{19}$ Therefore, the high burden of benzodiazepine non-medical use in Uganda's psychiatric patients raises concerns on medication safety.

We found that being inpatients favoured CPD nonmedical use, and that being inpatients and tobacco consumption favoured CPD non-medical and illicit drug use combined. Typically, it is severely ill patients who are admitted into inpatient care. Therefore, there could be a role of CPD non-medical use in severe mental illnesses in Uganda. Tobacco consumption is a known gateway to nonmedical controlled drug use. ${ }^{37}$ Elevated odds of CPD nonmedical and illicit drug use among tobacco consumers have been reported in several studies. ${ }^{21} 30313438$ Routine clinical screening and urine assays of these high-risk categories of patients for CPD non-medical use are necessary. In chronic pain patients, random drug testing significantly reduced the prevalence of illicit drug use ${ }^{50}$ Combination of baseline and random periodic drug testing is another option. ${ }^{19}$

Lifetime use of CPDs was also disproportionately high for benzodiazepines among patients with mental disorders in Uganda. Problematic CPD use is typically ignited by index exposure through medical prescription or unauthorised channels like recreation and social networks. ${ }^{1} 215152$ History of CPD lifetime use strongly predicts non-medical use. ${ }^{35} 51$ The US opioid crisis is attributed to the exponential rise in opioid prescriptions for chronic pain. ${ }^{725253}$ Therefore, high exposure to benzodiazepines among Uganda's psychiatric patients ought to be mitigated. Vigilant screening of patients for drug use disorder risk, education of clinicians on judicious prescribing and dispensers on appropriate dispensing, tight control of CPD access and prescription drug monitoring programmes are necessary. ${ }^{1053-57}$

High formative education and previous treatment at a substance abuse facility favoured lifetime use. Highly educated people are possibly more exposed to stressful situations, are more aware of the effects and availability of CPDs, or have higher access to these drugs than other people. However, previous studies have reported inconsistent relationships between education level and CPD non-medical use. One study of patients on prescribed chronic opioid therapy found that low education level independently favoured opioid use disorders ${ }^{26}$ while studies of benzodiazepine use disorders found no association. ${ }^{23} 58$ Meanwhile, non-medical use of one controlled drug or substance typically culminates into use of other drugs and/or poly-drug use. ${ }^{23} 3132345159$ Therefore, high level vigilance in clinical screening is needed to ensure CPD non-medical use is not missed in mentally ill patients previously treated for substance abuse.

The high burden of CPD non-medical use among patients with mental disorders suggests that vigilance and professionalism in their prescription and control needs improvement. It would also be useful to investigate how the sole use of clinical screening/assessment impacts mental health treatment outcomes in Uganda. There is also need for enhanced vigilance in clinical and laboratory screening of high risk patient categories identified here.

This study derives strengths in the high power of the sample, fair representation of different psychiatric disorders and patient categories (inpatients vs outpatients) and wide geographical coverage of Uganda. Further strength derives from the combined use of patient records and urine assays to detect non-medical use. We used a convenience sample of only those patients attending public mental clinics which excluded those outside care and those attending private mental health clinics. Affluent patients and those with institutional health insurance have broad choice of care providers and could be underrepresented at public clinics, yet they are the ones most likely to afford CPDs. A study of CPD non-medical use among patients at private mental clinics is necessary. Our study sites were also in large urban centres where access to CPDs is easy. It is possible that a different pattern of CPD non-medical and illicit drug use could be observed among patients from rural settings where CPD supply is limited. Furthermore, not all the 1275 study participants provided urine, although the 988 who did so was still large. Lastly, we did not investigate if the CPD nonmedical use was problematic or not. 
Author affiliations

${ }^{1}$ Department of Pharmacy, College of Health Sciences, Makerere University, Kampala, Uganda

${ }^{2}$ Department of Pharmacology, Faculty of Medicine, Gulu University, Gulu, Uganda ${ }^{3}$ Department of Psychiatry, Butabika National Referral Mental Hospital, Kampala, Uganda

${ }^{4}$ Department of Internal Medicine, College of Health Sciences, Makerere University, Kampala, Uganda

Acknowledgements We thank the following research assistants who participated in data collection: Irene Kantono, Joseline Asio, Martin Omachar, Robert Biibi, Fred Mulindwa and Annet Nannyonga. We also thank the administrators of the NURTURE programme for being very supportive, particularly Harriet Nambooze for always attending to our needs expeditiously. Lastly, we thank all our study participants and the institutions that were study sites.

Contributors PFK conceived the study. PFK, NS, ROA and PB-K participated in design of the study. PFK, JM, PK, SB, AK and BBM analysed the data under the mentorship of NS, PB-K and ROA. PFK drafted the manuscript under the guidance of NS, ROA and PB-K. All authors reviewed, revised and approved the final manuscript.

Funding This work was supported by a NURTURE research fellowship on NIH/ Fogarty Grant Number D43TW01032, Fogarty International Center, National Institutes of Health.

Competing interests None declared.

Patient consent for publication Not required.

Ethics approval The study received prior approval from the Institutional Review Board of the School of Health Sciences, Makerere University (SHSREC REF: 2018-003) and the Uganda National Council of Science and Technology (HS203ES). Informed consent from the participant's next of kin or caring nurse and assent from the participant were obtained prior to administration of the study tools.

Provenance and peer review Not commissioned; externally peer reviewed.

Data availability statement Data are available in a public, open access repository. Extra data can be accessed via the Dryad data repository at http://datadryad.org/ with the doi:10.5061/dryad.ns1rn8ppb.

Supplemental material This content has been supplied by the author(s). It has not been vetted by BMJ Publishing Group Limited (BMJ) and may not have been peer-reviewed. Any opinions or recommendations discussed are solely those of the author(s) and are not endorsed by BMJ. BMJ disclaims all liability and responsibility arising from any reliance placed on the content. Where the content includes any translated material, BMJ does not warrant the accuracy and reliability of the translations (including but not limited to local regulations, clinical guidelines, terminology, drug names and drug dosages), and is not responsible for any error and/or omissions arising from translation and adaptation or otherwise.

Open access This is an open access article distributed in accordance with the Creative Commons Attribution Non Commercial (CC BY-NC 4.0) license, which permits others to distribute, remix, adapt, build upon this work non-commercially, and license their derivative works on different terms, provided the original work is properly cited, appropriate credit is given, any changes made indicated, and the use is non-commercial. See: http://creativecommons.org/licenses/by-nc/4.0/.

ORCID iD

Pakoyo Fadhiru Kamba http://orcid.org/0000-0001-5169-0767

\section{REFERENCES}

1 Katzung BG. Basic and clinical pharmacology. 10th edn. New York: McGraw-Hill, 2007.

2 Hulme S, Bright D, Nielsen S. The source and diversion of pharmaceutical drugs for non-medical use: a systematic review and meta-analysis. Drug Alcohol Depend 2018;186:242-56.

3 Novak SP, Håkansson A, Martinez-Raga J, et al. Nonmedical use of prescription drugs in the European Union. BMC Psychiatry 2016;16:274.

4 United Nations. Single convention on narcotic drugs, 1961, as amended by the 1972 protocol amending the single convention on narcotic drugs, 1961. New York, 1961.

5 United Nations. Convention on psychotropic substances 1971. New York, 1971.
6 United Nations. United nations convention against illicit traffic in narcotic drugs and psychotropic substances, 1988. New York, 1988.

7 McHugh RK, Nielsen S, Weiss RD. Prescription drug abuse: from epidemiology to public policy. J Subst Abuse Treat 2015;48:1-7.

8 Rusyniak DE. Neurologic manifestations of chronic methamphetamine abuse. Neurol Clin 2011;29:641-55.

9 Shear MD, Goodnough A. Trump plans to declare opioid epidemic a national emergency, 2017. Available: https://www.nytimes.com/2017/ 08/10us/politics/opioid-trump-emergency.html?mcubz=1 [Accessed 19 Aug 2017].

10 Tedesco D, Asch SM, Curtin C, et al. Opioid abuse and poisoning: trends in inpatient and emergency department discharges. Health Aff 2017;36:1748-53.

11 United Nations Office on Drugs and Crime. World drug report 2018: opioid crisis, prescription drug abuse expands; cocaine and opium hit record highs. Vienna, 2018.

12 Colfax G, Santos G-M, Chu P, et al. Amphetamine-group substances and HIV. Lancet 2010;376:458-74.

13 United Nations Office on Drugs and Crime. Drug use in Nigeria. Vienna, 2018

14 Plüddemann A, Myers BJ, Parry $\mathrm{CDH}$. Surge in treatment admissions related to methamphetamine use in Cape town, South Africa: implications for public health. Drug Alcohol Rev 2008;27:185-9.

15 Salm-Reifferscheidt L. Tramadol: Africa's opioid crisis. Lancet 2018;391:1982-3.

16 Degenhardt L, Hall W. Extent of illicit drug use and dependence, and their contribution to the global burden of disease. Lancet 2012;379:55-70.

17 Bing EG, Burnam MA, Longshore D, et al. Psychiatric disorders and drug use among human immunodeficiency virus-infected adults in the United States. Arch Gen Psychiatry 2001;58:721-8.

18 Moran LV, Ongur D, Hsu J, et al. Psychosis with methylphenidate or amphetamine in patients with ADHD. N Engl J Med 2019;380:1128-38.

19 Gudin JA, Mogali S, Jones JD, et al. Risks, management, and monitoring of combination opioid, benzodiazepines, and/or alcohol use. Postgrad Med 2013;125:115-30.

20 Deyo RA, Mirza SK, Turner JA, et al. Overtreating chronic back pain: time to back off? J Am Board Fam Med 2009;22:62-8.

21 Dobscha SK, Morasco BJ, Duckart JP, et al. Correlates of prescription opioid initiation and long-term opioid use in veterans with persistent pain. Clin J Pain 2013;29:102-8.

22 Edlund MJ, Martin BC, Fan M-Y, et al. Risks for opioid abuse and dependence among recipients of chronic opioid therapy: results from the TROUP study. Drug Alcohol Depend 2010;112:90-8.

23 Kurtz SP, Buttram ME, Surratt HL. Benzodiazepine dependence among young adult participants in the club scene who use drugs. $J$ Psychoactive Drugs 2017;49:39-46.

24 Önen NF, Barrette E-P, Shacham E, et al. A review of opioid prescribing practices and associations with repeat opioid prescriptions in a contemporary outpatient HIV clinic. Pain Pract 2012;12:440-8.

25 Sullivan MD, Edlund MJ, Zhang L, et al. Association between mental health disorders, problem drug use, and regular prescription opioid use. Arch Intern Med 2006;166:2087-93.

26 Grattan A, Sullivan MD, Saunders KW, et al. Depression and prescription opioid misuse among chronic opioid therapy recipients with no history of substance abuse. Ann Fam Med 2012;10:304-11.

27 Wilsey BL, Fishman SM, Tsodikov A, et al. Psychological comorbidities predicting prescription opioid abuse among patients in chronic pain presenting to the emergency department. Pain Med 2008;9:1107-17.

28 Mackesy-Amiti ME, Donenberg GR, Ouellet LJ. Prescription opioid misuse and mental health among young injection drug users. Am J Drug Alcohol Abuse 2015;41:100-6.

29 Edlund MJ, Sullivan M, Steffick D, et al. Do users of regularly prescribed opioids have higher rates of substance use problems than nonusers? Pain Med 2007;8:647-56.

30 Fowler IL, Carr VJ, Carter NT, et al. Patterns of current and lifetime substance use in schizophrenia. Schizophr Bull 1998;24:443-55.

31 McCabe SE, Teter CJ, Boyd CJ. Medical use, illicit use, and diversion of abusable prescription drugs. $J$ Am Coll Health 2006:54:269-78.

32 Inciardi JA, Surratt HL, Kurtz SP, et al. Mechanisms of prescription drug diversion among drug-involved club- and street-based populations. Pain Med 2007;8:171-83.

33 Asher AK, Hahn JA, Couture M-C, et al. People who inject drugs, HIV risk, and HIV testing uptake in sub-Saharan Africa. J Assoc Nurses AIDS Care 2013;24:e35-44. 
34 Becker WC, Fiellin DA, Gallagher RM, et al. The association between chronic pain and prescription drug abuse in veterans. Pain Med 2009;10:531-6.

35 McCabe SE, West BT, Teter CJ, et al. Trends in medical use, diversion, and nonmedical use of prescription medications among college students from 2003 to 2013: connecting the dots. Addict Behav 2014;39:1176-82.

36 Degenhardt L, Mathers B, Guarinieri M, et al. Meth/amphetamine use and associated HIV: implications for global policy and public health. Int J Drug Policy 2010;21:347-58.

37 Degenhardt L, Stockings E, Patton G, et al. The increasing global health priority of substance use in young people. Lancet Psychiatry 2016;3:251-64.

38 Taremian F, Yaghubi $\mathrm{H}$, Pairavi $\mathrm{H}$, et al. Risk and protective factors for substance use among Iranian university students: a national study. Subst Abuse Treat Prev Policy 2018;13:46.

39 Mental Disability Advocacy Center,. Mental health Uganda. psychiatric hospitals in Uganda: a human rights investigation, 2014.

40 Ministry of Health. Annual health sector performance report: financial year 2013/2014. Kampala, 2014.

41 Bartlett II JE, Kotrlik JW, Higgins CC. Organizational research: determining appropriate sample size in survey research. Information Technology, Learning, and Performance Journal 2001;19:43-50.

42 United Nations Office on Drugs and Crime. World drug report 2019. Vienna, 2019.

43 Sara GE, Large MM, Matheson SL, et al. Stimulant use disorders in people with psychosis: a meta-analysis of rate and factors affecting variation. Aust N Z J Psychiatry 2015;49:106-17.

44 Awuzu EA, Kaye E, Vudriko P. Prevalence of cannabis residues in psychiatric patients: a case study of two mental health referral hospitals in Uganda. Subst Abuse 2014;8:SART.S13254-5.

45 Government of Uganda. The National drug policy and authority act, (cap 206. Kampala, 1993.

46 Government of Uganda. The narcotic drugs and psychotropic substances (control) act, 2015. Kampala, 2015.

47 Schmidt LG, Grohmann R, Müller-Oerlinghausen B, et al. Prevalence of benzodiazepine abuse and dependence in psychiatric in-patients with different nosology. An assessment of hospital-based drug surveillance data. $\mathrm{Br} J$ Psychiatry 1989;154:839-43.

48 Longo LP, Johnson B. Addiction: Part I. Benzodiazepines-side effects, abuse risk and alternatives. Am Fam Physician 2000;61:2121-8.

49 Manchikanti L, Singh A. Therapeutic opioids: a ten-year perspective on the complexities and complications of the escalating use, abuse, and nonmedical use of opioids. Pain Physician 2008;11:S63-88.

50 Manchikanti L, Manchukonda R, Pampati V, et al. Does random urine drug testing reduce illicit drug use in chronic pain patients receiving opioids? Pain Physician 2006;9:123-9.

51 Edlund MJ, Martin BC, Russo JE, et al. The role of opioid prescription in incident opioid abuse and dependence among individuals with chronic noncancer pain: the role of opioid prescription. Clin J Pain 2014;30:557-64.

52 Salsitz EA, Pain C. Chronic pain, chronic opioid addiction: a complex nexus. J Med Toxicol 2016;12:54-7.

53 Okie S. A flood of opioids, a rising tide of deaths. N Engl J Med 2010;363:1981-5.

54 Dart RC, Surratt HL, Cicero TJ, et al. Trends in opioid analgesic abuse and mortality in the United States. N Engl J Med 2015;372:241-8.

55 Rigg KK, Kurtz SP, Surratt HL. Patterns of prescription medication diversion among drug dealers. Drugs 2012;19:145-55.

56 United States General Accounting Office. GAO-04-110 prescription drugs: OxyContin abuse and diversion and efforts to address the problem. Washington, DC, 2003.

57 Dowell D, Haegerich TM, Chou R. CDC Guideline for Prescribing Opioids for Chronic Pain-United States, 2016. JAMA 2016;315:1624-45.

58 Kurtz SP, Surratt HL, Levi-Minzi MA, et al. Benzodiazepine dependence among multidrug users in the club scene. Drug Alcoho Depend 2011;119:99-105.

59 Inciardi JA, Surratt HL, Cicero TJ, et al. Prescription opioid abuse and diversion in an urban community: the results of an ultrarapid assessment. Pain Med 2009;10:537-48. 